\title{
Development of a Canadian Adaptation of the Facts on Aging Quiz
}

\author{
Edward Helmes \\ Department of Psychology, James Cook University, Townsville, Australia \\ Email: edward.helmes@jcu.edu.au
}

Received 7 April 2016; accepted 9 May 2016; published 13 May 2016

Copyright (C) 2016 by author and Scientific Research Publishing Inc.

This work is licensed under the Creative Commons Attribution International License (CC BY). http://creativecommons.org/licenses/by/4.0/

(c) $\underset{\mathrm{EY}}{\text { (i) Open Access }}$

\begin{abstract}
Accurate knowledge about older adults is desirable for research into aging populations. The Palmore Facts on Aging Quiz (FAQ) has been one of the most widely used measures of knowledge about aging that has been used in English-speaking countries. The original true-false version has largely been replaced by the current multiple-choice format. Here I present data on a Canadian multiple-choice FAQ from 172 older adult residents in the community with a mean age of 70.3 years old $(S D=8.88)$. The mean percentage correct on the Canadian FAQ-2C was $54.4 \%$, a proportion higher than the recent Australian data and some older American data on older adults. The Canadian adaptation of the modified Australian multiple-choice version demonstrates the value of the local verification of FAQ items' scoring key if the knowledge assessed by the FAQ is to be used accurately in a different country or if the local scoring key was developed several years earlier.
\end{abstract}

\section{Keywords}

Aging, Older Adults, Knowledge, Scale Development

\section{Introduction}

Aging populations are currently a feature of many countries of the world. This is particularly evident for those countries like Canada that experienced a baby-boom in the years following World War II. Such countries are particularly likely to have demographic features that make the direct adoption and widespread use of measures based on American data, such as the Palmore Facts on Aging Quiz [1] (FAQ), questionable. Adaptation of the scoring key and relevant text may be required or desirable. Previous work [2] resulted in the development of the Canadian adaptation of the original true-false version of the FAQ, but no adapted form of the multiple-choice version is available for Canadian use.

In addition to changing demographic factors, changes in the policies of governments with regard to social and 
health-care programs can lead to alterations in a correct response in the scoring keys. This would be particularly true for multiple-choice variations of the FAQ [3] [4] where the stem and the four response alternatives may need revision in whole or in part. Responses that were correct at one time may become incorrect as policies and practices evolved with time in company with demographic shifts. Measures of the extent of knowledge about older adults are increasingly important, given the evidence of extensive negative attitudes toward older adults [5] that in turn may be based upon false stereotypes of older adults. The degree to which older adults share those negative attitudes has not been well-determined in the current literature [5].

Pachana, Helmes, and Gudgeon [6] found several original FAQ items to have incorrectly keyed answers for modern Australia. Accurate knowledge of older adults is presumed to be necessary for changing negative attitudes. The level of knowledge among students, especially those in the health care sciences, is important if the health problems of older adults are not going to be treated by younger providers with inaccurate knowledge of older adults. However, the knowledge of older about their own age cohort is also important because of the adoption of negative self-stereotypes [5] that can act to exaggerate the negative aspects of ageing. Expectations about one's own aging are often based upon such stereotypes and objective measures about older adults' knowledge are essential for efforts to counter the negative stereotypes. Adapting content and the scoring key increase the face validity of a measure, which argue in favour of a Canadian adaptation of the older versions of the FAQ.

The first goal here is to describe a Canadian updating of the Australian multiple-choice FAQ-2 in order to provide a corrected scoring key for current use of the FAQ in Canada. Experience with the original FAQ in Australia revealed several items that had a majority of responses that were keyed as incorrect, which would increase error variance in the total score. If relatively few items on the Australian adaptation with a Canadian sample need modification, then the second goal is to explore the degree to which older Canadians are knowledgeable about the aging of the Canadian population.

\section{Methods}

\subsection{Participants}

Community-dwelling older adults in Fredericton, NB volunteered their time to complete the resulting Canadian adaptation. A total of 172 older adults (119 females) with a mean age of 70.3 years (SD = 8.88; range 50 to 94$)$ took part. Recruitment was through the membership of two community groups affiliated with St. Thomas University and 101 who responded to a newspaper article. The only selection criterion applied was the willingness to participate. A total of 308 forms were distributed, resulting in a return rate of $56 \%$. The great majority were white, English-speaking and from the city and its suburbs. Ethical approval for the study was obtained through the St. Thomas University Research Ethics Board (\#2013-14). Participants received an information sheet that provided a description of the study and contact details of the experimenter. Consent was implied through return of the completed forms.

\subsection{Procedure}

The version of the FAQ-2 that was used for adaptation is the recent Australian variation [6], which was used as the most recently published version. Students in the upper-level undergraduate gerontology class of GERO3031A provided fact-checking for the 25 FAQ-2 items. Following fact-checking, the scoring keys for four items were altered. For item 15 on widows, Statistics Canada [7] reported for the 2011 census that the correct ratio of widows to widowers is close to 5:1. For item 16 on interest in political matters, Turcott and Schellenberg [8] reported that the age group of 55 to 64 was the group most frequently searching for information on political issues in the previous year. Item 17 on being appointed to a government position proved difficult to verify. Both the Public Service Commission of Canada [9] and the Organization for Economic Co-operation and Development (OECD) [10] suggest that the average age of appointment to the civil service is well under 65 years. For item 25 on the proportion widowed, the currently correct answer was for a slow increase in the number of widowed [7]. A copy of the revised form is reported in Appendix 1. The verified correct answer is indicated for each item. The maximum correct score is 25. Other changes were made to those items with obviously Australian (or American) references, but a complete editing to reword all items was not undertaken in order to maximize continuity with earlier versions.

Basic descriptive statistics were calculated for all 25 items. Item-total correlations were not calculated due to 
the heterogeneous item content of the FAQ.

\section{Results}

Table 1 reports the proportion of respondents who gave the correct answer, as well as the 95\% confidence intervals. In comparison to the Australian data of $51.5 \%$ correct (95\% CI: 0.43 to 0.60 ) [6], the Canadian sample obtained a mean of $54.3 \%$ (95\% CI: 0.50 to 0.58 ) correct versus the American data of $41.0 \%$ correct (95\% CI: 0.35 to 0.47 ) [4]. The two easiest items were 2 (illness) and 14 (law abiding) with about $90 \%$ of respondents getting those two items correct. At the other end of the spectrum, items 11 (income) and 21 (poverty) were answered correctly by about $10 \%$ of the respondents.

\section{Discussion}

This adaptation of the FAQ required changes to four items, which is less than in previously published adaptations. The Australian adaptation of the FAQ-2 [6] required alterations to nine items, which was approximately

Table 1. Mean number of correct item responses and 95\% confidence intervals for the FAQ-2C.

\begin{tabular}{|c|c|c|}
\hline FAQ-2C Item Number and Content & Mean Proportion Correct & 95\% Confidence Interval \\
\hline 1: Height & 0.87 & $0.81-0.92$ \\
\hline 2: Illness Limitation & 0.90 & $0.83-0.94$ \\
\hline 3: Illness Frequency & 0.81 & $0.74-0.87$ \\
\hline 4: Injuries & 0.59 & $0.50-0.67$ \\
\hline 5: Absenteeism & 0.05 & $0.02-0.10$ \\
\hline 6: Life Expectancy & 0.65 & $0.56-0.73$ \\
\hline 7: Gender Life Expectancy & 0.80 & $0.72-0.86$ \\
\hline 8: Medicare Payments & 0.56 & $0.47-0.64$ \\
\hline 9: Social Security & 0.58 & $0.49-0.66$ \\
\hline 10: Pension Plan & 0.30 & $0.22-0.39$ \\
\hline 11: Income & 0.14 & $0.08-0.21$ \\
\hline 12: Crime Victims & 0.16 & $0.10-0.23$ \\
\hline 13: Fear of Crime & 0.72 & $0.64-0.79$ \\
\hline 14: Law-abiding & 0.90 & $0.82-0.94$ \\
\hline 15: Widows & 0.24 & $0.17-0.32$ \\
\hline 16: Interest in Politics & 0.32 & $0.24-0.40$ \\
\hline 17: Appointments & 0.54 & $0.45-0.63$ \\
\hline 18: First Nations Aged & 0.34 & $0.26-0.42$ \\
\hline 19: Volunteers & 0.34 & $0.26-0.43$ \\
\hline 20: Living Context & 0.36 & $0.28-0.45$ \\
\hline 21: Poverty & 0.09 & $0.01-0.15$ \\
\hline 22: First Nations Poverty & 0.76 & $0.67-0.82$ \\
\hline 23: Reduced Activity & 0.88 & $0.81-0.97$ \\
\hline 24: Children Leaving & 0.57 & $0.48-0.65$ \\
\hline 25: Widowed Rate & 0.44 & $0.35-0.52$ \\
\hline
\end{tabular}


the same as the eight items adapted by Luszcz [11] for an Australian variant of the original true-false FAQ. The adaptation for use of the FAQ in New Zealand [12] required the modification of even more items. One example of shifts in statistics that may need adaptation is the increase in body mass index for older adults reported for Australia [13]. The current results suggest that the majority of items concerning factual data on older adults on modern versions of the FAQ in English-speaking countries in the developed world are accurate. They also suggest that there have not been major demographic shifts in recent years in the above countries.

The Australian sample [6] reported somewhat more items correct than did the original American sample. Here, the Canadian sample of older adults did somewhat better again on the FAQ-2C. Reasons for these disparities are not entirely obvious and are not clearly related to the percentage of older adults in the population in these different countries, but it may be that older people are learning more about aging. However, the FAQ was not developed using accepted methods of test construction and further replication samples would be needed to confirm these findings before deletion of any items could be recommended. Future studies could investigate these issues in more depth as well as explore the adaptation of the FAQ to different, non-English speaking countries.

The limitations of this study include the sample being drawn from a geographic area that is not representative of the urban residents of Canada. The sample represents volunteers with an interest in aging from a city on the Canadian east coast, which makes it somewhat atypical of community-dwelling older Canadian adults.

\section{Conclusion}

Having questionnaires that evaluate knowledge of older adults is valuable for both local and international studies. The establishment of a modern adaptation of the FAQ should allow more accurate determinations of the state of knowledge of older adults in Canada.

\section{Acknowledgements}

I thank the staff and students of the Gerontology Department at St. Thomas University, Frederickton, NB for their hospitality during my time there as Visiting Chair in 2013.

\section{References}

[1] Palmore, E.B. (1998) Facts on Aging Quiz: A Handbook of Uses and Results. 2nd Edition, Springer, New York.

[2] Matthews, A.M., Tindale, J.A. and Norris, J.E. (1984) The Facts on Aging Quiz: A Canadian Validation and CrossCultural Comparison. Canadian Journal on Aging, 3, 165-174. http://dx.doi.org/10.1017/S0714980800004785

[3] Harris, D.K. and Changas, P.S. (1994) Revision of Palmore’s Second Facts on Aging Quiz from a True-False to a Multiple-Choice Format. Educational Gerontology, 20, 741-754. http://dx.doi.org/10.1080/0360127940200802

[4] Harris, D.K., Changas, P.S. and Palmore, E.B. (1996) Palmore’s First Facts on Aging Quiz in a Multiple-Choice Format. Educational Gerontology, 22, 575-589. http://dx.doi.org/10.1080/0360127960220605

[5] Nelson, T.D. (2002) Ageism: Stereotyping and Prejudice against Older Persons. MIT Press, Cambridge.

[6] Pachana, N.A., Helmes, E. and Gudgeon, S. (2013) An Australian Facts on Ageing Quiz. Australasian Journal on Ageing, 32, 117-121. http://dx.doi.org/10.1111/j.1741-6612.2012.00635.x

[7] Statistics Canada (2014) 2011 Census. Population by Marital Status and Sex. Table 051-0042. Statistics Canada, Ottawa.

[8] Turcott, M. and Schellenberg, G. (2007) A Portrait of Seniors in Canada 2006 (Cat. No. 89-519). Statistics Canada, Ottawa. www.statcan.gc.ca/pub/89-519-x/89-519-x2006001-eng.pdf

[9] Public Service Commission of Canada (2014) 2012-2014 Annual Report (Cat. No.SC1-2014E). Statistics Canada, Ottawa.

[10] Organization for Economic Co-Operation and Development (OECD) (2012) Human Resources Management Country Profiles Canada. Author, Paris. http://www.oecd.org/gov/pem/OECD\%20HRM\%20Profile\%20-\%20Canada.pdf

[11] Luszcz, M.A. (1982) Facts on Aging: An Australian Validation. Gerontologist, 22, 369-372. http://dx.doi.org/10.1093/geront/22.4.369

[12] Pennington, H.R., Pachana, N.A., and Coyle, S.L. (2001) Use of the Facts on Aging Quiz in New Zealand: Validation of the Questions, Performance of Student Sample, and Effects of a Don’t Know Option. Educational Gerontology, 27, 409-416. http://dx.doi.org/10.1080/03601270152053438

[13] Australian Bureau of Statistics (2003) Health Risk Factors, Australia, 2001 (Cat. No. 4812.0). Author, Canberra. 


\section{FAQ-2C}

\section{Please circle the letter marking the correct response to the following questions and statements.}

1. In old age, a person's height

A Does not change

B Only appears to change

C* Tends to decline

$\mathrm{D}$ Depends on how active one is

2. Compared with younger persons, more older persons (65 or over) are limited in their activity by which type of illness?

A Acute illnesses (short term)

B Colds and flu

C Infections

D* Chronic illnesses

3. Which type of illness do older persons have less frequently than younger persons?

A Chronic illness

B Arthritis

C Stroke

D* Acute illness

4. Compared with younger persons, older persons have

A* More injuries in the home

$\mathrm{B}$ About the same number of injuries in the home

C Fewer injuries in the home

D Twice the likelihood to be injured in the home

5. Older workers' absenteeism rates

A Are higher than among younger workers

B Cannot be trusted

C Are about the same as among younger workers

D* Are lower than among younger workers

6. The life expectancy of First Nations people at age 65

A Is higher than that of whites

B* Is lower than that of whites

$\mathrm{C}$ Is about the same as that of whites

D Has not been determined

7. Men's life expectancy at age 65 compared with women's

A* Is lower

$\mathrm{B}$ Is dropping

$\mathrm{C}$ Is about the same

D Is higher

8. What percent of medical expenses for the aged does Medicare pay?
A About 15 to 25 percent
B Nearly 50 percent
C* About 75 to 85 percent
D Nearly 100 percent 
9. Social security benefits

A* Automatically increase with inflation

B Are not subject to change

C Must be adjusted by parliament

D Are often cut back to balance the deficit

10. The Canada (Quebec) Pension Plan and Old Age Security plan :

A* Guarantee a minimum income for the needy elderly

B Provide extra income for all elderly

C Supplement the income of the elderly in nursing homes

D Pay medical expenses for the elderly

11. As for income

A The majority of elderly live below the poverty level.

B The elderly are the poorest age group in our society.

C* The elderly get their proportionate share of the nation's income.

D The income gap between the elderly and younger people is widening.

12. Compared with younger persons, rates of criminal victimisation among the elderly are

A Higher

B* Lower

C About the same

D Steadily increasing

13. Fear of crime among the elderly

A* Is higher than among younger persons

$B$ Is about the same as among younger persons

C Is lower than among younger persons

D Is not significant

14. The most law abiding adults are

A Those in their $20 \mathrm{~s}$

B Those in their $30 \mathrm{~s}$

C Those 45 to 65

D* Those over 65

15. Comparing widows with widowers among the aged

A Their numbers are about equal.

$\mathrm{B}$ There are more than twice as many widows as widowers

C* There are more than 5 times as many widows as widowers

$\mathrm{D}$ There are more than twice as many widowers as widows

16. The age group who have the greatest interest in political matters are

A* People over 65

B People aged 55 to 64

C People aged 40 to 54

D People aged 20 to 39

17. Being elected or appointed to a government position is

A Rare among those over 65

B* More frequent among those under 65

C More frequent among those over 65

D Similar in frequency among older and younger persons 
18. The proportion of First Nations people among the aged is A* Growing

B Declining

C. Staying about the same

D. Small compared with other minority groups

19. Participation in voluntary organisations usually

A* Does not decline among healthy older persons

$B$ Declines among healthy older persons

C Increases among healthy older persons

$\mathrm{D}$ Is highest among healthy youth

20. The majority of old people live:

A Alone

B In long-stay institutions

C* With their spouses

D With their children

21. The rate of poverty among the elderly is

A* Lower than among those under 65

B Higher than among those under 65

C The same as it is for other age groups

D High as a result of their fixed incomes

22. The rate of poverty among aged First Nations people is A Less than that of whites

B About the same as that of whites

C* Greater than that of whites

D No different to other Indigenous age groups

23. Older persons who reduce their activity tend to be

A Happier than those who remain active

B* Not as happy as those who remain active

C About as happy as others

D Healthier

24. When the last child leaves home, the majority of parents

A Have serious problems of adjustment

B* Have higher levels of life satisfaction

C Try to get their children to come back home

D Suffer from the "empty nest" syndrome

25. The proportion widowed among the aged:

A Is gradually decreasing

$\mathrm{B}^{*}$ Is gradually increasing

C Has remained the same in this century

D Is unrelated to longevity

Note: Correct answers are noted by *.

Note: A French translation is available from the author. 